\title{
Treatment with olopatadine and naphazoline hydrochloride reduces allergic conjunctivitis in mice through alterations in inflammation, NGF and VEGF
}

\author{
LIN QUAN $^{1}$ and HUA HE ${ }^{2}$ \\ ${ }^{1}$ Department of Visual Science and Optometry, The People's Hospital of Guangxi, Nanning, \\ Guangxi 530021, P.R. China; ${ }^{2}$ Ocular Surface Center, Miami, FL 33173, USA
}

Received March 19, 2015; Accepted December 8, 2015

DOI: $10.3892 / \mathrm{mmr} .2016 .4937$

\begin{abstract}
The aim of the current study was to investigate whether olopatadine and naphazoline hydrochloride reduce allergic conjunctivitis in mice through alterations in inflammation, NGF and VEGF. An allergic conjunctivitis mouse model was established using histamine or an antigen (ovalbumin), following which mice were treated with $1 \%$ olopatadine solution and/or $0.2 \mathrm{mg} / \mathrm{ml}$ of naphazoline hydrochloride. Histamine or antigen-induced conjunctival vascular hyperpermeability was examined and the levels of inflammatory factors, cytokines, IgE, GMCSF and NGF were analyzed using ELISA in antigen-induced conjunctival vascular hyperpermeability mice. In addition, VEGF protein expression was measured using western blotting in antigen-induced mice. The results indicated that olopatadine and naphazoline hydrochloride significantly suppressed conjunctival dye leakage in mice with histamine or antigen-induced conjunctival vascular hyperpermeability. In addition, treatment with olopatadine and naphazoline hydrochloride was able to reduce the levels of inflammatory factors (TNF- $\alpha$, IL-1 $\beta$ and IL-6), cytokines (IFN- $\gamma$ and IL-4), IgE, GMCSF, and NGF in antigen-induced conjunctival vascular hyperpermeability mice. The protein expression levels of VEGF in antigen-induced conjunctival vascular hyperpermeability mice were reduced following treatment with olopatadine and naphazoline hydrochloride. These results suggest that treatment with olopatadine and naphazoline hydrochloride reduces conjunctivitis in mice via effects on inflammation, NGF and VEGF.
\end{abstract}

Correspondence to: Mr. Lin Quan, Department of Visual Science and Optometry, The People's Hospital of Guangxi, 6 Taoyuan Road, Nanning, Guangxi 530021, P.R. China

E-mail: hehuausa@163.com

Key words: olopatadine, naphazoline hydrochloride, conjunctivitis, inflammation, nerve growth factor, vascular endothelial growth factor

\section{Introduction}

Allergic conjunctivitis is a common ocular allergic disease, with a high incidence of $20 \%$ of the total population in China (1). It predominantly occurs as a result of type I and IV hypersensitivity, of which the main symptoms include ocular itching, frequently with conjunctival hyperemia and edema (2). Allergic conjunctivitis is divided into the following clinical subtypes: i) Seasonal allergic conjunctivitis; ii) perennial allergic conjunctivitis; iii) vernal keratoconjunctivitis; iv) atopic keratoconjunctivitis; and v) giant papillary conjunctivitis (3). Diagnosis and classification of allergic conjunctivitis is predominantly based on clinical features, laboratory or pathological tests (4).

The early reactions in the pathogenesis of allergic conjunctivitis are mediated by mast cells and T cells. Following contact with the allergen, the antigen is combined with specific immunoglobulin E (IgE), resulting in mast cell degranulation and the release of inflammatory mediators (5). Mast cell degranulation activates endothelial cells, promoting the expression of chemokines and adhesion molecules (6). This attracts inflammatory cells to the conjunctival membrane, and activates conjunctival fibroblasts and epithelial cells to participate in the generation of conjunctivitis, with this process occurring within a few seconds following contact with the antigen, and the effects lasting from tens of minutes to several hours (7). In addition, interleukins (ILs) are released by fibroblasts, and mast cells are activated and release secondary messengers, promoting the allergic reaction to enter the late phase (8). The released cytokines, including IL-4, IL-5, IL-6, IL- 8, IL-13, tumor necrosis factor- $\alpha$ (TNF- $\alpha$ ) and vascular cell adhesion molecule-1, act on the conjunctiva and recruit inflammatory cells, including eosinophils, basophils, neutrophils and helper $\mathrm{T}$ lymphocytes, producing the second peak of immune inflammatory reaction (9).

Naphazoline hydrochloride is an adrenergic drug, stimulating adrenergic $\alpha$-receptors resulting in vasoconstriction (10). Clinically, it is predominantly used for allergic and inflammatory nasal congestion, acute and chronic rhinitis and eye congestion. Additionally, it is also used for bacterial and allergic conjunctivitis and reduces blepharospasm (11). Olopatadine is a drug with dual effects, as a selective 
antagonist of histamine 1 receptors and a stabilizer of mast cells, and works faster than non-steroidal anti-inflammatory agents and mast cell stabilizers (12). However, the effects and mechanisms of olopatadine and naphazoline hydrochloride on allergic conjunctivitis remain to be fully elucidated. The current study hypothesized that olopatadine and naphazoline hydrochloride are able to reduce allergic conjunctivitis in mice, with the mechanism involved associated with effects on inflammation, nerve growth factor (NGF) and vascular endothelial growth factor (VEGF).

\section{Materials and methods}

Animals. A total of 40 female wild-type BALB/c mice (4-5 weeks; $18 \mathrm{~g} \pm 2 \mathrm{~g}$ ) were housed in the facilities of the Health Sciences Center of The People's Hospital of Guangxi (Guangxi, China) and maintained following the Use of Animals in Research and the internal animal use guidelines (13). All mice were maintained at $23 \pm 2^{\circ} \mathrm{C}$ and $55 \%$ humidity with a $12 / 12 \mathrm{~h}$ light/dark cycle, and received sterilized food and water ad libitum. The present study was approved by the Ethics Committee of Guangxi People's Hospital.

Study groups. The mice were divided into five groups: i) Control group (Con; $n=8)$, mice received physiological saline $[0.1 \mathrm{~m} / 100 \mathrm{~g}$, intraperitoneal injection (i.p.)]; ii) allergic conjunctivitis model group ( $\mathrm{AC} ; \mathrm{n}=8)$, mice were induced by histamine (30 $\mu 1,0.1 \mathrm{mg} / \mathrm{ml}$; Sigma-Aldrich) or ovalbumin (OVA; $30 \mu \mathrm{l}$ ); iii) olopatadine (Sigma-Aldrich, St. Louis, MO, USA) group (OLO; $n=8)$, allergic conjunctivitis mice received $0.1 \%$ olopatadine solutions (10 $\mu$ l per eye) (14); iv) naphazoline hydrochloride (Sigma-Aldrich) group $(\mathrm{NH}$; $\mathrm{n}=8$ ), allergic conjunctivitis mice received $0.2 \mathrm{mg} / \mathrm{ml}$ naphazoline hydrochloride (10 $\mu \mathrm{l}$ per eye) (15); v) olopatadine and naphazoline hydrochloride group (OLO $+\mathrm{NH}$; $n=8)$, allergic conjunctivitis mice received $1 \%$ olopatadine solutions and $0.2 \mathrm{mg} / \mathrm{ml}$ of naphazoline hydrochloride (10 $\mu \mathrm{l}$ per eye) (11)

Histamine-induced conjunctival vascular hyperpermeability inmice. The mice were narcotized with pentobarbital $(50 \mathrm{mg} / \mathrm{kg}$, i.p.), then injected with $30 \mu \mathrm{l}$ of histamine $(0.1 \mathrm{mg} / \mathrm{ml})$ in the upper subconjunctiva following the intravenous injection of $1.5 \% \mathrm{w} / \mathrm{v}$ Evans blue solution. At $30 \mathrm{~min}$ following treatment, the mice were sacrificed by decollation following anesthesia with pentobarbital sodium (50 mg/kg; Sigma-Aldrich) and the treated eye was immediately removed. The tissue sample was extracted using formamide at $45^{\circ} \mathrm{C}$ for $5 \mathrm{~min}$ and the absorbance was determined using a spectrophotometer (3550; Bio-Rad Laboratories, Inc., Hercules, CA, USA) at $625 \mathrm{~nm}$. Values were analyzed as per weight of each eye.

Antigen-induced conjunctival vascular hyperpermeability in passively sensitized mice. The mice were narcotized with pentobarbital $(50 \mathrm{mg} / \mathrm{kg}$, i.p.), then injected with $30 \mu 1$ anti-OVA antiserum (cat. no. C6534; rabbit anti-chicken; Sigma-Aldrich) in the upper subconjunctiva. Subsequently, $48 \mathrm{~h}$ later the animals were subjected to a challenge by an intravenous injection of OVA ( $2 \mathrm{mg} / \mathrm{ml})$ with $1.5 \% \mathrm{w} / \mathrm{v}$ Evans blue solution. At $30 \mathrm{~min}$ following treatment, the mice were sacrificed and the treated eye was immediately removed.
Normal saline (10-20 $\mu \mathrm{l})$ was applied to the tissue sample for $30 \mathrm{~min}$ and the absorbance was determined using a spectrophotometer (3550; Bio-Rad Laboratories, Inc., Hercules, CA, USA) at $625 \mathrm{~nm}$. Values were analyzed as per weight of each organization.

Measurement of inflammation. The peripheral blood was collected from the tail vein and centrifuged at $12,000 \mathrm{x} \mathrm{g}$ for $10 \mathrm{~min}$ at $4^{\circ} \mathrm{C}$ and the supernatants were collected. TNF- $\alpha$, IL-1 $\beta$ and IL-6 levels were measured using commercially available enzyme-linked immunosorbent assay (ELISA) kits according to the manufacturer's instructions (Lianshuo Biological Technology Co., Ltd., Shanghai, China).

Measurement of cytokine levels. The peripheral blood was collected from the tail vein and centrifuged at $12,000 \mathrm{x} \mathrm{g}$ for $10 \mathrm{~min}$ at $4^{\circ} \mathrm{C}$ and the supernatants were collected. Interferon (IFN) $-\gamma$ and IL-4 levels were measured using commercially available ELISA kits according to the manufacturer's instructions (Lianshuo Biological Technology Co., Ltd.).

Measurement of IgE levels. The peripheral blood was collected from the tail vein and centrifuged at $12,000 \mathrm{x} \mathrm{g}$ for $10 \mathrm{~min}$ at $4^{\circ} \mathrm{C}$ and the supernatants were collected. The $\mathrm{IgE}$ levels were measured using a commercially available ELISA kit according to the manufacturer's instructions (Lianshuo Biological Technology Co., Ltd.).

Measurement of granulocyte-macrophage colony-stimulating factor (GMCSF). Conjunctivas were removed at room temperature. The removed tissue was immediately homogenized in phosphate-buffered saline $(\mathrm{pH}$ 7.4) containing a protease inhibitor (Shanghai Sangon Biological Engineering Technology, Shanghai, China). The samples were centrifuged at $12,000 \times \mathrm{g}$ for $10 \mathrm{~min}$ at $4^{\circ} \mathrm{C}$ and the supernatants were collected. The GMCSF level was measured using a commercially available ELISA kit according to the manufacturer's instructions (Lianshuo Biological Technology Co., Ltd.).

Measurement of NGF level. Conjunctivas were removed at room temperature. The removed tissue was immediately homogenized in phosphate buffered saline $(\mathrm{pH} 7.4)$ containing a protease inhibitor. The samples were centrifuged at $12,000 \times \mathrm{g}$ for $10 \mathrm{~min}$ at $4^{\circ} \mathrm{C}$ and the supernatants were collected. The NGF level was measured using a commercially available ELISA kit according to the manufacturer's instructions (Lianshuo Biological Technology Co., Ltd.).

Western blot analysis. Conjunctivas were removed at room temperature and immediately homogenized in phosphate buffered saline ( $\mathrm{pH}$ 7.4) containing a protease inhibitor. The samples were centrifuged at $12,000 \mathrm{xg}$ for $10 \mathrm{~min}$ at $4^{\circ} \mathrm{C}$ and the supernatants were collected. The protein content of the samples was quantified using a bicinchoninic acid assay (Nanjing Jiancheng Bioengineering Institute, Nanjing, China). Equal amounts of proteins $(50 \mu \mathrm{g})$ were separated using $12 \%$ sodium dodecyl sulfate polyacrylamide gel (Sangon Biotech Co., Ltd., Shanghai, China) electrophoresis and transferred to a nitrocellulose membrane (EMD Millipore, Billerica, MA, USA). The membrane was incubated with antibodies against goat 
polyclonal anti-VEGF $(1: 1,000$; cat. no. sc-1876; Santa Cruz Biotechnology, Inc., Dallas, TX, USA) and goat polyclonal $\beta$-actin (1:500; cat. no. sc-1616; Santa Cruz Biotechnology, Inc.) overnight at $4^{\circ} \mathrm{C}$ with agitation. The proteins were detected using horseradish peroxidase-conjugated anti-rabbit secondary antibodies (1:5,000; cat. no. sc-2793; Santa Cruz Biotechnology, Inc.) at room temperature and visualized with an enhanced chemiluminescence system (GE Healthcare, Piscataway, NJ, USA).

Statistical analysis. Values are presented as the mean \pm standard error. SPSS software, version 17 (SPSS, Inc., Chicago, IL, USA) was used for the statistical analysis. Statistical analysis was performed using a one way analysis of variance. $\mathrm{P}<0.05$ was considered to indicate a statistically significant difference.

\section{Results}

Olopatadine and naphazoline hydrochloride reduce histamine-induced conjunctival vascular hyperpermeability in mice. To investigate the effects of olopatadine and naphazoline hydrochloride on histamine-induced conjunctival vascular hyperpermeability, mice were induced with histamine. The amount of conjunctival dye leakage following the injection of histamine was increased. Treatment with olopatadine or naphazoline hydrochloride reduced the levels of conjunctival dye leakage compared with the AC group (Fig. 1). Combined treatment with olopatadine and naphazoline hydrochloride further reduced conjunctival dye leakage in histamine-induced mice, compared with the olopatadine alone group (Fig. 1).

Olopatadine and naphazoline hydrochloride reduce antigen-induced conjunctival vascular hyperpermeability in mice. To investigate whether treatment with olopatadine and naphazoline hydrochloride reduces antigen-induced conjunctival vascular hyperpermeability, mice were induced using OVA. The amount of conjunctival dye leaked following the injection of the OVA antigen was significantly increased. Treatment with olopatadine or naphazoline hydrochloride reduced the level of conjunctival dye leakage compared with the AC group (Fig. 2). Combined treatment with olopatadine and naphazoline hydrochloride further reduced conjunctival dye leakage in antigen-induced mice, compared with the olopatadine alone group (Fig. 2).

Olopatadine and naphazoline hydrochloride reduce inflammation in mice with antigen-induced conjunctival vascular hyperpermeability. The effect of olopatadine and naphazoline hydrochloride on inflammatory factors was investigated in mice with antigen-induced conjunctival vascular hyperpermeability. Following OVA antigen induction, the levels of TNF- $\alpha$, IL-1 $\beta$ and IL-6 were observed to increase. Treatment with olopatadine or naphazoline hydrochloride reduced the levels of the inflammatory factors compared with the AC group (Fig. 3). Combined treatment witholopatadine and naphazolinehydrochloridefurther reduced the levels of the inflammatory factors in antigen-induced mice, compared with the olopatadine alone group (Fig. 3).

Olopatadine and naphazoline hydrochloride reduce cytokine levels in mice with antigen-induced conjunctival vascular

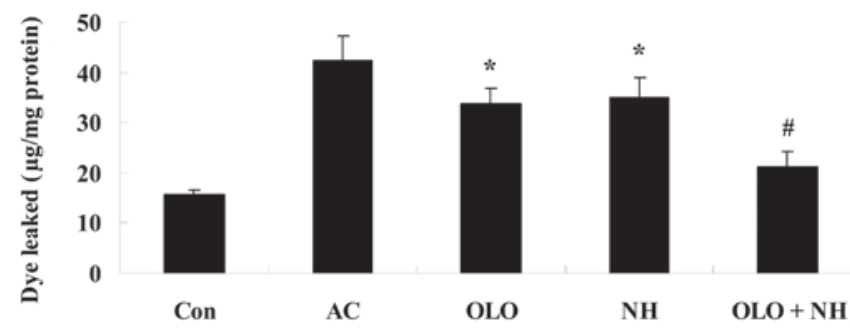

Figure 1. Treatment with OLO and NH reduces histamine-induced conjunctival vascular hyperpermeability in mice. ${ }^{*} \mathrm{P}<0.01$ vs. the AC group; ${ }^{\#} \mathrm{P}<0.01$ vs. the OLO group. OLO, olopatadine; NH, naphazoline hydrochloride; Con, control; AC, allergic conjunctivitis model group.
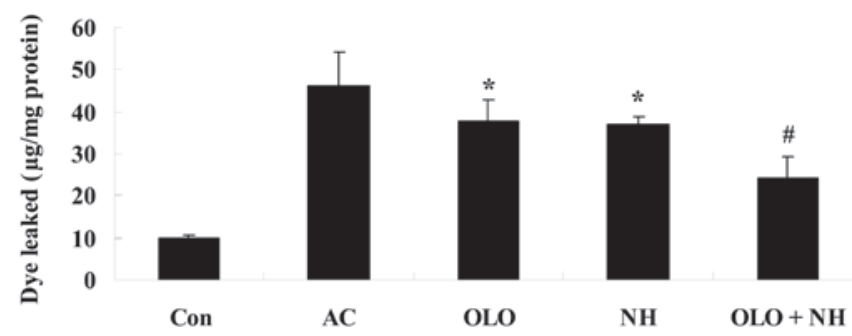

Figure 2. Treatment with OLO and NH reduces antigen-induced conjunctival vascular hyperpermeability in mice. ${ }^{*} \mathrm{P}<0.01$ vs. the $\mathrm{AC}$ group; ${ }^{*} \mathrm{P}<0.01$ vs. the OLO group. OLO, olopatadine; $\mathrm{NH}$, naphazoline hydrochloride; Con, control; AC, allergic conjunctivitis model group.
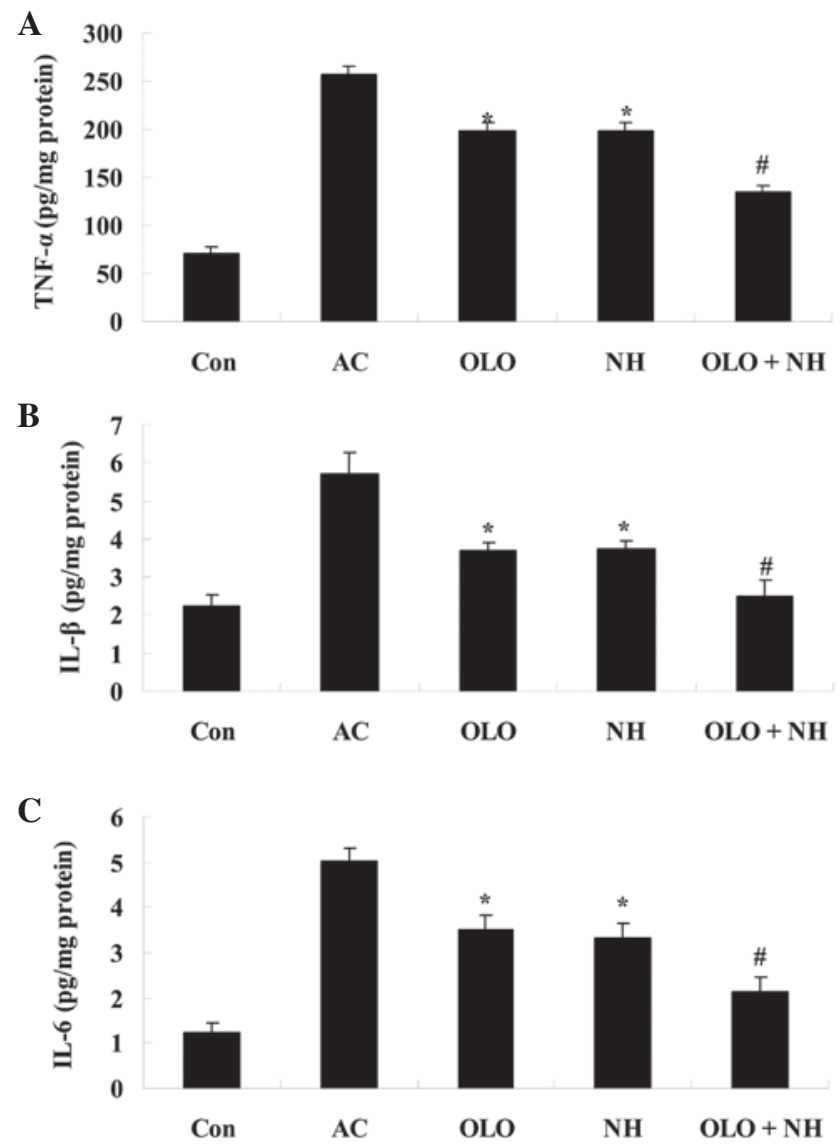

Figure 3. Treatment with OLO and NH reduces the levels of inflammatory factors: (A) TNF- $\alpha$, (B) IL-1 $\beta$ and (C) IL-6 in antigen-induced mice. "P<0.01 vs. the $\mathrm{AC}$ group; ${ }^{*} \mathrm{P}<0.01$ vs. the OLO group. OLO, olopatadine; $\mathrm{NH}$, naphazoline hydrochloride; Con, control; AC, allergic conjunctivitis model group. TNF- $\alpha$, tumor necrosis factor- $\alpha$; IL, interleukin. 
A

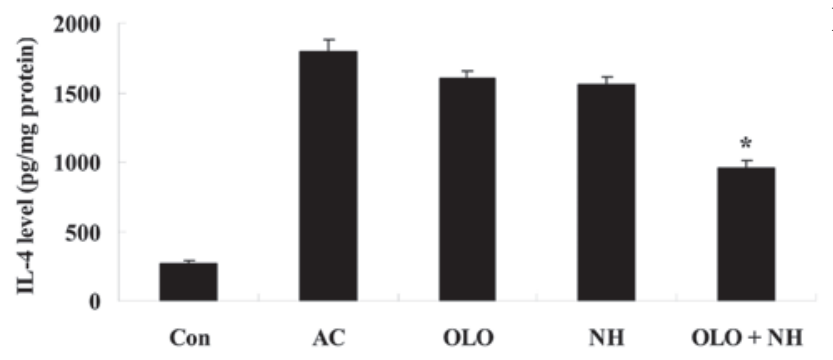

B

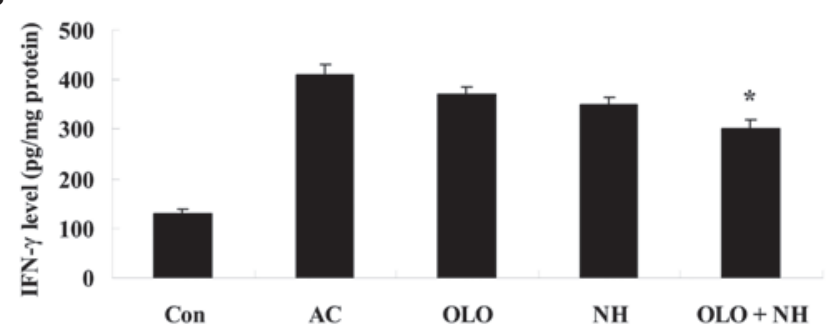

Figure 4. Combined treatment with OLO and NH reduces the levels of cytokines: (A) IL-4 and (B) IFN- $\gamma$ in antigen-induced mice. * $\mathrm{P}<0.01$ vs. the AC group. OLO, olopatadine; NH, naphazoline hydrochloride; Con, control; AC, allergic conjunctivitis model group; IL-4, interleukin 4; IFN- $\gamma$, interferon $\gamma$.

hyperpermeability. To further explore the effects of olopatadine and naphazoline hydrochloride, the cytokine levels were measured in mice with antigen-induced conjunctival vascular hyperpermeability. The IFN- $\gamma$ and IL-4 levels were increased in antigen-induced mice. Treatment with olopatadine or naphazoline hydrochloride resulted in a reduction in the cytokine levels, however this was not a statistically significant difference compared with the AC group (Fig. 4). Combined treatment with olopatadine and naphazoline hydrochloride significantly reduced the levels of IFN- $\gamma$ and IL-4 in antigen-induced mice, compared with the olopatadine alone group (Fig. 4).

Olopatadine and naphazoline hydrochloride reduce the levels of $I g E$ in mice with antigen-induced conjunctival vascular hyperpermeability. Fig. 5 indicates that the levels of IgE were increased in antigen-induced mice. Treatment with olopatadine or naphazoline hydrochloride reduced the levels of $\operatorname{IgE}$ compared with the AC group (Fig. 5). Combined treatment with olopatadine and naphazoline hydrochloride further reduced the levels of $\mathrm{IgE}$ level in antigen-induced mice, compared with the olopatadine alone group (Fig. 5).

Olopatadine and naphazoline hydrochloride reduce the levels of GMCSF level in mice with antigen-induced conjunctival vascular hyperpermeability. Fig. 6 indicates that the levels of GMCSF were increased in antigen-induced mice. Treatment with olopatadine or naphazoline hydrochloride reduced the levels of GMCSF compared with the AC group (Fig. 6). Combined treatment with olopatadine and naphazoline hydrochloride further reduced the levels of GMCSF in antigen-induced mice, compared with the olopatadine alone group (Fig. 6).

Olopatadine and naphazoline hydrochloride reduce the levels of NGF in mice with antigen-induced conjunctival vascular hyperpermeability. Fig. 7 indicates that the levels of NGF were increased in antigen-induced mice. Treatment with olopatadine or naphazoline hydrochloride reduced the levels of NGF compared with the AC group (Fig. 7). Combined treatment with olopatadine and naphazoline hydrochloride further reduced the levels of NGF in antigen-induced mice, compared with the olopatadine alone group (Fig. 7).

Olopatadine and naphazoline hydrochloride reduce the expression levels of VEGF in mice with antigen-induced conjunctival vascular hyperpermeability. To investigate the

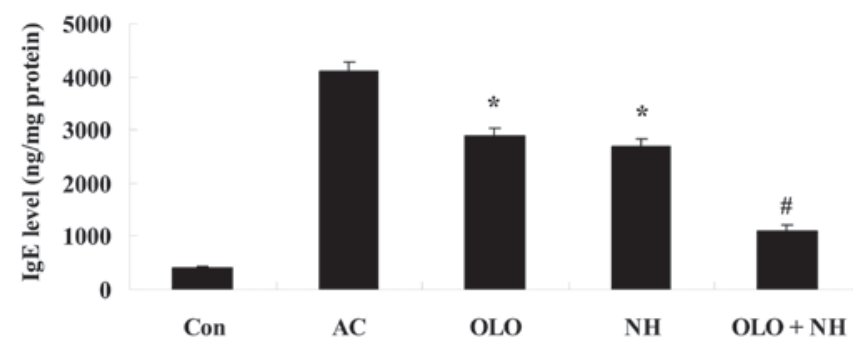

Figure 5. Treatment with OLO and NH reduces the level of $\operatorname{IgE}$ in antigen-induced mice. ${ }^{*} \mathrm{P}<0.01$ vs. the AC group; ${ }^{*} \mathrm{P}<0.01$ vs. the OLO group. OLO, olopatadine; $\mathrm{NH}$, naphazoline hydrochloride; Con, control; AC, allergic conjunctivitis model group; IgE, immunoglobulin E.

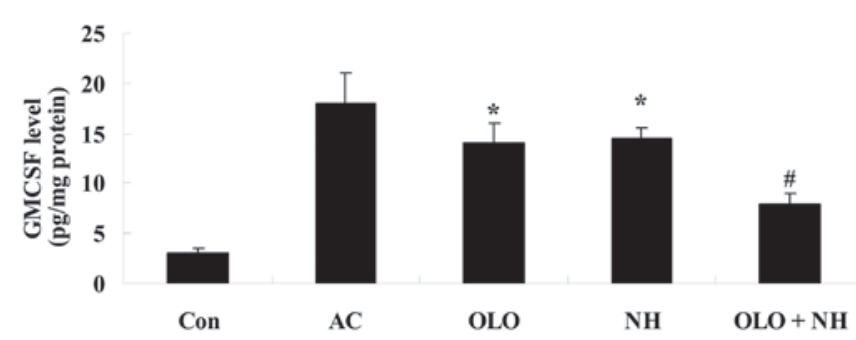

Figure 6. Treatment with OLO and NH reduces the levels of GMCSF in antigen-induced mice. ${ }^{*} \mathrm{P}<0.01$ vs. the AC group; ${ }^{\prime \prime} \mathrm{P}<0.01$ vs. the OLO group. OLO, olopatadine; $\mathrm{NH}$, naphazoline hydrochloride; Con, control; AC, allergic conjunctivitis model group; GMCSF, granulocyte-macrophage colony-stimulating factor.

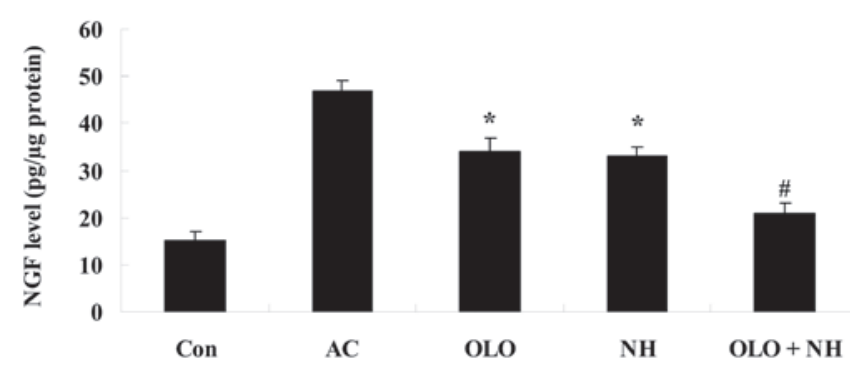

Figure 7. Treatment with OLO and NH reduces the levels of NGF in antigen-induced mice. ${ }^{*} \mathrm{P}<0.01$ vs. the $\mathrm{AC}$ group; ${ }^{\text {"}} \mathrm{P}<0.01$ vs. the $\mathrm{OLO}$ group. OLO, olopatadine; $\mathrm{NH}$, naphazoline hydrochloride; Con, control; AC, allergic conjunctivitis model group; NGF, nerve growth factor.

effects of olopatadine and naphazoline hydrochloride upon VEGF protein expression in antigen-induced mice, the VEGF expression levels were measured using western blot analysis. 
A

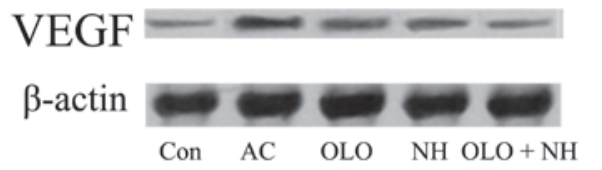

B

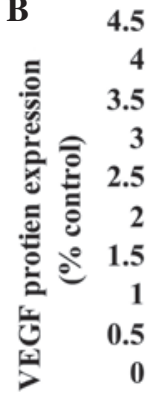

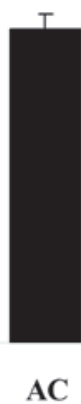

AC

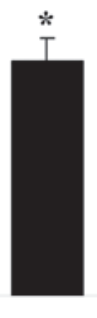

OLO

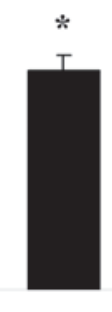

NH

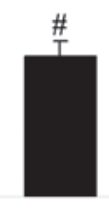

$\mathrm{OLO}+\mathrm{NH}$

Figure 8. Treatment with OLO and NH reduces the expression levels of VEGF in antigen-induced mice. (A) VEGF protein expression was measured using western blotting and (B) the expression levels were quantified. ${ }^{*} \mathrm{P}<0.01$ vs. the AC group; ${ }^{\#} \mathrm{P}<0.01$ vs. the OLO group. OLO, olopatadine; NH, naphazoline hydrochloride; VEGF, vascular endothelial growth factor; Con, control; AC, allergic conjunctivitis model group.

Fig. 8 indicates that antigen induction increased the expression levels of VEGF. Treatment with olopatadine or naphazoline hydrochloride suppressed the elevation of VEGF protein expression compared with the AC group (Fig. 8). Combined treatment with olopatadine and naphazoline hydrochloride further reduced the VEGF expression levels in antigen-induced mice, compared with the olopatadine alone group (Fig. 8).

\section{Discussion}

Conjunctivitis is a common ocular surface disease with various etiologies, which present with similar symptoms including eye irritation, eye watering, increased secretions and congestion (16). The symptoms of conjunctivitis have a rapid onset and may result in a degree of damage to the ocular tissue, and in severe cases may result in blindness, and additional adverse consequences (17). Severe bacterial keratitis is a sight-threatening disease, which may result in various degrees of vision loss, with lesions in the central corneal area potentially resulting in reductions in vision, and in severe cases, corneal ulcers and corneal perforation, which may eventually require corneal transplant (18). The present study demonstrated that olopatadine and naphazoline hydrochloride significantly reduced the level of conjunctival dye leakage in mice with histamine or antigen-induced conjunctival vascular hyperpermeability.

Conjunctival infection may result in systemic inflammatory responses, and induce increases in the levels of the inflammatory cytokines, IL-1 $\beta$, IL-6 and TNF- $\alpha$ (19). Previous studies have indicated that IL-1 $\beta$ is an important inflammatory cytokine, contributing to inflammatory injuries and the occurrence of autoimmune diseases, and participating in an autocrine loop composed of inflammatory mediators including IL-6, TNF- $\alpha$ and neutrophils (20-22). The cytokines IL- 6 and TNF- $\alpha$ exhibit important biological activities and are generated by a variety of immune cells in the body, such as monocyte-macrophage cells (23). In the present study, TNF- $\alpha$, IL-1 $\beta$ and IL-6 levels were reduced following treatment with olopatadine and naphazoline hydrochloride in mice with antigen-induced conjunctival vascular hyperpermeability. Murota et al (24) demonstrated that olopatadine reduced the elevated levels of inflammatory markers in NC/Nga mice (24). Tamura et al (25) showed that olopatadine significantly reduced IL-1 $\beta$ and IL- 6 levels induced by the repeated topical application of oxazolone in rats. However, in the present study the effect of naphazoline hydrochloride on inflammatory factors was unremarkable. The effect of olopatadine solutions and naphazoline hydrochloride on inflammatory factors may be predominantly concerned with olopatadine.

Previous studies have demonstrated that cluster of differentiation (CD)4+ T cells may be further divided into Th1-type and Th2-type cells, according to the surface identity and function of the T lymphocyte cell subsets (26-28). Under normal conditions, the Th1/Th2 system of the body maintains a state of equilibrium; Th1 cell subsets secrete IL-2, IFN- $\gamma$ and TNF- $\alpha$ to activate macrophages, with these cells involved in mediating delayed hypersensitivity responses, which may inhibit the function of Th2 cells in stimulating B lymphocytes for IgE synthesis (29). Th2 cells generate IL-4, 5, 6, 13, 10 and GMCSF, which induces the differentiation and recruitment of eosinophils, inducing the transformation of B cell immunoglobulin subtypes and promoting IgE synthesis and mediating humoral immune responses (30). The present study demonstrated that the combined treatment with olopatadine and naphazoline hydrochloride reduced cytokine levels (IFN- $\gamma$ and IL-4) in mice with antigen-induced conjunctival vascular hyperpermeability. Tamura et al (25) previously demonstrated that olopatadine is able to ameliorate IFN- $\gamma$ and IL-4 levels in a rat model of experimental cutaneous inflammation (31).

Allergic conjunctivitis is a type-1 hypersensitivity, mediated by IgE, and eosinophil cationic protein is the biomarker of eosinophil activity and is able to damage mucosa epithelium (32). In addition, eosinophilic basic protein may result in severe allergic damage (31). A previous study observed that the levels of total $\operatorname{IgE}$ and specific $\operatorname{IgE}$ are raised in the plasma and tears of patients with allergic conjunctivitis. In addition, B lymphocytes that express CD23, CD21 and CD40 in conjunctival lymphoid follicles were activated, suggesting that this type of B lymphocyte may be the precursor cells for IgE synthesis, and the conjunctiva may serve a catalytic role in IgE synthesis (33). In the present study, it was observed that the IgE levels in the olopatadine and naphazoline hydrochloride treated group was lower compared with the olopatadine or naphazoline hydrochloride alone groups. Cook et al (34) reported that olopatadine inhibits the levels of $\operatorname{IgE}$ in human conjunctival mast cells.

GMCSF is able to stimulate the proliferation and differentiation of early pluripotent hematopoietic stem cells and 
granulocyte-monocyte progenitor cells, and enhance the collaboration capabilities of mature neutrophils, eosinophils and monocyte-macrophages $(35,36)$. Additionally, GMSCF stimulates the growth of erythroid and granulocyte-macrophage progenitor cells in addition to proliferative hematopoetic progenitor cells, which prolong the survival time of macrophages and enhance the anti-tumor capabilities. Furthermore GMCSF is able to stimulate endothelial cell growth and prevent the apoptosis of various cells (37). GMCSF is an important indicator of inflammatory stress within the body (38). In the present study, the GMCSF levels in the olopatadine and naphazoline hydrochloride combination treatment group were lower compared with the olopatadine or naphazoline hydrochloride alone groups. Tamura et al (39) indicated that olopatadine hydrochloride reduced the inflammatory rebound phenomenon via the suppression of IL-1 $\beta$, IL-4, IL-18 and GMCSF levels in mice with chronic contact hypersensitivity.

Under normal physiological conditions, NGF is a neurotrophic factor (40). The elevated levels of NGF in inflammatory reactions have been indicated to result in the aggravation of pain (41). Previous studies have indicated that proinflammatory cytokines (IL-1 $\beta$, TNF- $\alpha$ ) are closely associated with NGF, and promote an increase in the levels of NGF (42-44). In addition, NGF may act on proinflammatory cytokines in turn (45). It has been demonstrated that NGF is able to inhibit inflammation in inflammatory bowel disease, with increased levels of NGF serving a protective role in the inflammatory reaction, and suggesting that NGF may in turn act on proinflammatory cytokines, to inhibit the excessive expression of proinflammatory cytokines in a potential bio-feedback regulation mechanism (45-47). In the current study, the NGF levels were reduced by the treatment with olopatadine and naphazoline hydrochloride in mice with antigen-induced conjunctival vascular hyperpermeability. Tamura et al (48) demonstrated that repeated pretreatment with olopatadine inhibited NGF and VEGF production in rats (48).

VEGF is a growth factor with heparin-binding activity, which was purified from the substrate of follicular stellate cells of bovine pituitary by Ferrara in 1989 for the first time $(49,50)$. VEGF exerts a strong mitogenic effect on endothelial cells and is regarded as a vascular endothelial cell-specific mitogen, inducing the proliferation of vascular endothelial cells and promoting angiogenesis (51). The biological activity of VEGF depends on the expression levels, the distribution of the target cell receptors and its integration with the receptors (52). Previous studies have demonstrated that hypoxia results in the high expression of VEGF, and that the alteration in retinal microvascular permeability in diabetic retinopathy is associated with VEGF $(52,53)$. In addition, VEGF and the corresponding receptor are integrated, resulting in retinal endothelial cell proliferation, migration and contributing to the formation of new blood vessels which destroy the blood-retina shielding protection in retinal endothelial cells (54). The current study observed that olopatadine and naphazoline hydrochloride were able to reduce the expression levels of VEGF in mice with antigen-induced conjunctival vascular hyperpermeability. Tamura et al (55) suggested that the anti-allergic activity of olopatadine reduced VEGF levels in sensitized rats.

In conclusion, the current study demonstrated that treatment with olopatadine and naphazoline hydrochloride reduces histamine or antigen-induced conjunctival vascular hyperpermeability in mice. In addition, treatment with olopatadine and naphazoline hydrochloride reduces inflammatory reactions and the levels of IL-1 $\beta$, IL- 6 , IFN- $\gamma$ and IL-4. Furthermore, treatment with olopatadine and naphazoline hydrochloride reduces the levels of IgE, GMCSF, NGF and VEGF in antigen-induced conjunctival vascular hyperpermeability mice. These results suggest that olopatadine and naphazoline hydrochloride are potential treatments for non-bacterial conjunctivitis.

\section{References}

1. Fujishima H, Ohashi Y and Takamura E: Efficacy of epinastine hydrochloride ophthalmic solution in allergic conjunctivitis by conjunctival cedar pollen allergen challenge. Ann Allergy Asthma Immunol 113: 476-481, 2014.

2. Irkec MT and Bozkurt B: Molecular immunology of allergic conjunctivitis. Curr Opin Allergy Clin Immunol 12: 534-539, 2012.

3. Williams JI, Kennedy KS, Gow JA, Torkildsen GL, Abelson MB, Gomes PJ and McNamara TR; Bepotastine Besilate Ophthalmic Solutions Study Group: Prolonged effectiveness of bepotastine besilate ophthalmic solution for the treatment of ocular symptoms of allergic conjunctivitis. J Ocul Pharmacol Ther 27: 385-393, 2011.

4. Sgrulletta R, Bonini S, Lambiase A and Bonini S: Allergy and infections: Long-term improvement of vernal keratoconjunctivitis following viral conjunctivitis. Eur J Ophthalmol 16: 470-473, 2006.

5. Chen H, Yang HW, Wei JF and Tao AL: In silico prediction of the T-cell and IgE-binding epitopes of Per a 6 and Bla g 6 allergens in cockroaches. Mol Med Rep 10: 2130-2136, 2014.

6. Lopes-Ferreira M, Gomes EM, Bruni FM, Ferreira MJ, Charvet $\mathrm{P}$ and Lima $\mathrm{C}$ : First report of interruption of mast cell degranulation and endothelial cells activation by anti-inflammatory drugs controlling the acute response provoked by Pseudoplatystoma fasciatum fish venom. Toxicon 90: 237-248, 2014.

7. Lam DS, Fan DS, Ng JS, Yu CB, Wong CY and Cheung AY: Ocular hypertensive and anti-inflammatory responses to different dosages of topical dexamethasone in children: A randomized trial. Clin Experiment Ophthalmol 33: 252-258, 2005.

8. Kase S, Yokoi M, Ishida S and Kase M: Measurement of interleukins in vitreous infusion fluid. Biomed Rep 3: 818-820, 2015.

9. Waisbourd M, Levinger E, Varssano D, Moisseiev E, Zayit-Soudri S, Barak A, Loewenstein A and Barequet I: High-dose topical bevacizumab for corneal neovascularization. Pharmacology 92: 310-314, 2013.

10. Pemberton JD, MacIntosh PW,Zeglam A and Fay A: Naphazoline as a confounder in the diagnosis of carotid artery dissection. Ophthal Plast Reconstr Surg 31: e33-35, 2015.

11. Greiner JV and Udell IJ: A comparison of the clinical efficacy of pheniramine maleate/naphazoline hydrochloride ophthalmic solution and olopatadine hydrochloride ophthalmic solution in the conjunctival allergen challenge model. Clin Ther 27: 568-577, 2005.

12. McLaurin EB, Marsico NP, Ackerman SL, Ciolino JB, Williams JM, Villanueva L and Hollander DA: Ocular itch relief with alcaftadine $0.25 \%$ versus olopatadine $0.2 \%$ in allergic conjunctivitis: Pooled analysis of two multicenter randomized clinical trials. Adv Ther 31: 1059-1071, 2014.

13. Tamura T: Olopatadine ophthalmic solution suppresses substance $\mathrm{P}$ release in the conjunctivitis models. Asia Pac Allergy 2: 115-121, 2012.

14. Souri E, Amanlou M, Farsam H and Afshari A: A rapid derivative spectrophotometric method for simultaneous determination of naphazoline and antazoline in eye drops. Chem Pharm Bull (Tokyo) 54: 119-122, 2006.

15. Berger WE, Ratner PH, Casale TB, Meltzer EO and Wall GM: Safety and efficacy of olopatadine hydrochloride nasal spray $0.6 \%$ in pediatric subjects with allergic rhinitis. Allergy Asthma Proc 30: 612-623, 2009.

16. Curran JP, Nunez JR and Visconti E: Primary meningococcal conjunctivitis. N Y State J Med 89: 634-635, 1989.

17. Joob B and Wiwanitkit V: Rasanjana Madhu Ashchyotana for a mucopurulent conjunctivitis. Ayu 33: 146, 2012. 
18. Kuo PC, Lin JY, Chen LC, Fang YT, Cheng YC, Wu HY, Tsai CY, Chen YS, Lin SY, Wu CL and Ling QD: Molecular and immunocytochemical identification of coxsackievirus A-24 variant from the acute haemorrhagic conjunctivitis outbreak in Taiwan in 2007. Eye (Lond) 24: 131-136, 2010.

19. Rank RG, Bowlin AK, Tormanen KI, Wang Y and Maurelli AT: Effect of inflammatory response on in vivo competition between two chlamydial variants in the guinea pig model of inclusion conjunctivitis. Infect Immun 80: 612-619, 2012.

20. Fernandez-Robredo P, Recalde S, Moreno-Orduña M, García-García L, Zarranz-Ventura J and García-Layana A: Azithromycin reduces inflammation in a rat model of acute conjunctivitis. Mol Vis 19: 153-165, 2013.

21. Li Y, Zhang Z, Zhao J, Li H, Ren K and Xing R: Influences of Bushen Xingnao Decoction on expression of vascular endothelia growth factor, IL- $1 \beta$ and tumor necrosis factor- $\alpha$ in vascular dementia rats. Pak J Pharm Sci 28: 2317-2320, 2015.

22. Borkenstein A, Faschinger C, Maier R, Weger M, Theisl A, Demel U, Graninger W, Irene H and Mossböck G: Measurement of tumor necrosis factor-alpha, interleukin-6, Fas ligand, interleukin- $1 \alpha$, and interleukin- $1 \beta$ in the aqueous humor of patients with open angle glaucoma using multiplex bead analysis. Mol Vis 19: 2306-2311, 2013.

23. Cavone L, Muzzi M, Mencucci R, Sparatore B, Pedrazzi M, Moroni $\mathrm{F}$ and Chiarugi A: $18 \beta$-glycyrrhetic acid inhibits immune activation triggered by HMGB1, a pro-inflammatory protein found in the tear fluid during conjunctivitis and blepharitis. Ocul Immunol Inflamm 19: 180-185, 2011.

24. Murota H, El-latif MA, Tamura T, Amano T and Katayama I: Olopatadine hydrochloride improves dermatitis score and inhibits scratch behavior in NC/Nga mice. Int Arch Allergy Immunol 153: 121-132, 2010

25. Tamura T, Matsubara M, Amano T and Chida M: Olopatadine ameliorates rat experimental cutaneous inflammation by improving skin barrier function. Pharmacology 81: 118-126, 2008.

26. Liu L, Rich BE, Inobe J, Chen W and Weiner HL: Induction of Th2 cell differentiation in the primary immune response: Dendritic cells isolated from adherent cell culture treated with IL-10 prime naive $\mathrm{CD}^{+}{ }^{+} \mathrm{T}$ cells to secrete IL-4. Int Immunol 10 : 1017-1026, 1998

27. Chen H, Luo Z, Shen H, Ren C, Li Z, Tang J, Wang J and Wu T: Research on the roles of transcription factors T-bet and GATA-3 in aplastic anemia. Clin Lab 60: 291-295, 2014.

28. Krzyzowska M, Polanczyk M, Bas M, Cymerys J, Schollenberger A, Chiodi F and Niemialtowski M: Mousepox conjunctivitis: The role of Fas/FasL-mediated apoptosis of epithelial cells in virus dissemination. J Gen Virol 86: 2007-2018, 2005.

29. Mello CB, Ramos L, Gimenes AD, Andrade TR, Oliani SM and Gil CD: Immunomodulatory effects of galectin-1 on an IgE-mediated allergic conjunctivitis model. Invest Ophthalmol Vis Sci 56: 693-704, 2015.

30. Wang Z and Davies JD: CD8 blockade promotes the expansion of antigen-specific $\mathrm{CD} 4^{+} \mathrm{FOXP} 3^{+}$regulatory $\mathrm{T}$ cells in vivo. Int Immunopharmacol 7: 249-265, 2007.

31. Eperon S, Berguiga M, Ballabeni P, Guex-Crosier C and Guex-Crosier Y: Total IgE and eotaxin (CCL11) contents in tears of patients suffering from seasonal allergic conjunctivitis. Graefes Arch Clin Exp Ophthalmol 252: 1359-1367, 2014.

32. Acar N, Toker E and Kazokoglu H: Tear and serum eosinophil cationic protein levels in seasonal allergic conjunctivitis. Eur J Ophthalmol 13: 671-675, 2003.

33. Mimura T, Amano S, Funatsu H, Yamagami S, Araie M, Kaji Y, Arimoto A, Ishida Y, Usui T and Okamoto S: Correlations between allergen-specific IgE serum levels in patients with allergic conjunctivitis in spring. Ocul Immunol Inflamm 12: 45-51,2004.

34. Cook EB, Stahl JL, Barney NP and Graziano FM: Olopatadine inhibits TNFalpha release from human conjunctival mast cells. Ann Allergy Asthma Immunol 84: 504-508, 2000.

35. Zhou W, Chu D, Sha W, Fu L and Li Y: Effects of granulocyte-macrophage colony-stimulating factor supplementation in culture medium on embryo quality and pregnancy outcome of women aged over 35 years. J Assist Reprod Genet: Dec 10, 2015 (Epub ahead of print)

36. Son BK, Sawaki D, Tomida S, Fujita D, Aizawa K, Aoki H, Akishita M, Manabe I, Komuro I,Friedman SL, et al: Granulocyte macrophage colony-stimulating factor is required for aortic dissection/intramural haematoma. Nat Commun 6: 6994, 2015.
37. Huang G, Sun T, Zhang L, Wu Q, Zhang K, Tian Q and Huo R Combined application of alginate dressing and human granulocyte-macrophage colony stimulating factor promotes healing in refractory chronic skin ulcers. Exp Ther Med 7: 1772-1776, 2014.

38. Min L, Isa SA, Fam WN, Sze SK, Beretta O, Mortellaro A and Ruedl C: Synergism between curdlan and GM-CSF confers a strong inflammatory signature to dendritic cells. J Immunol 188: $1789-1798,2012$

39. Tamura T, Matsubara M, Hasegawa K, Ohmori K and Karasawa A: Olopatadine hydrochloride suppresses the rebound phenomenon after discontinuation of treatment with a topical steroid in mice with chronic contact hypersensitivity. Clin Exp Allergy 35: 97-103, 2005.

40. Priyanka HP, Sharma U, Gopinath S, Sharma V, Hima L and ThyagaRajan S: Menstrual cycle and reproductive aging alters immune reactivity, NGF expression, antioxidant enzyme activities, and intracellular signaling pathways in the peripheral blood mononuclear cells of healthy women. Brain Behav Immun 32: 131-143, 2013.

41. Hu CP, Wu XR, Li QG, Sun ZW, Wang AP, Feng JT and Wang J: Proteomic analysis of NGF-induced transdifferentiation of adrenal medullary cells. Int J Mol Med 32: 347-354, 2013.

42. Mita S, Shimizu Y, Sato A, Notsu T, Imada K and Kyo S: Dienogest inhibits nerve growth factor expression induced by tumor necrosis factor- $\alpha$ or interleukin-1 $\beta$. Fertil Steril 101: 595-601, 2014.

43. Taishi P, Churchill L, De A, Obal F, Jr. and Krueger JM: Cytokine mRNA induction by interleukin-1beta or tumor necrosis factor alpha in vitro and in vivo. Brain Res 1226: 89-98, 2008

44. Antonelli A, Lapucci G, Vigneti E, Bonini S and Aloe L: Human lung fibroblast response to NGF, IL-1beta, and dexamethsone. Lung 183: 337-351, 2005.

45. Gruber HE, Hoelscher GL, Bethea S and Hanley EN, Jr.: Interleukin 1-beta upregulates brain-derived neurotrophic factor, neurotrophin 3 and neuropilin 2 gene expression and NGF production in annulus cells. Biotech Histochem 87: 506-511, 2012.

46. Vieira KP, de Almeida e Silva Lima Zollner AR, Malaguti C, Vilella CA and de Lima Zollner R: Ganglioside GM1 effects on the expression of nerve growth factor (NGF), Trk-A receptor, proinflammatory cytokines and on autoimmune diabetes onset in non-obese diabetic (NOD) mice. Cytokine 42: 92-104, 2008.

47. Ryan VH, German AJ, Wood IS, Hunter L, Morris P and Trayhurn P: NGF gene expression and secretion by canine adipocytes in primary culture: upregulation by the inflammatory mediators LPS and TNFalpha. Horm Metab Res 40: 861-868, 2008

48. Tamura $\mathrm{T}$ and Kimoto $\mathrm{N}$ : Efficacy of repeated pretreatment with olopatadine hydrochloride on rhinitis induced by intranasal instillation of toluene-2,4-diisocyanate in rats. Pharmacology 84: 288-293, 2009.

49. Yang WJ, Yang YN, Cao J, Man ZH, Li Y and Xing YQ: Paxillin regulates vascular endothelial growth factor A-induced in vitro angiogenesis of human umbilical vein endothelial cells. Mol Med Rep 11: 1784-1792, 2015.

50. Ferrara $\mathrm{N}$ and Henzel WJ: Pituitary follicular cells secrete a novel heparin-binding growth factor specific for vascular endothelial cells. Biochem Biophys Res Commun 161: 851-858, 1989.

51. Xu JY, Meng QH, Chong Y, Jiao Y, Zhao L, Rosen EM and Fan S: Sanguinarine is a novel VEGF inhibitor involved in the suppression of angiogenesis and cell migration. Mol Clin Oncol 1: 331-336, 2013.

52. Sahin E, Baycu C, Koparal AT, Burukoglu Donmez D and Bektur E: Resveratrol reduces IL-6 and VEGF secretion from co-cultured A549 lung cancer cells and adipose-derived mesenchymal stem cells. Tumour Biol: Dec 18, 2015 (Epub ahead of print).

53. Bills VL, Salmon AH, Harper SJ, Overton TG, Neal CR, Jeffery B, Soothill PW and Bates DO: Impaired vascular permeability regulation caused by the $\operatorname{VEGF}(1)(6)(5) b$ splice variant in pre-eclampsia. BJOG 118: 1253-1261, 2011.

54. Okabe K, Kobayashi S, Yamada T, Kurihara T, Tai-Nagara I, Miyamoto T, Mukouyama YS, Sato TN, Suda T, Ema M and Kubota Y: Neurons limit angiogenesis by titrating VEGF in retina. Cell 159: 584-596, 2014.

55. Tamura T: Investigation of the antiallergic activity of olopatadine on rhinitis induced by intranasal instillation of antigen in sensitized rats using thermography. Asia Pac Allergy 1: 138-144, 2011. 